\title{
Can Green Power Save Us from Climate Change?
}

\author{
M. SCOTt TAYLOR ${ }^{a}$
}

JEL-Classification: Q42, Q47, Q54

Keywords: environment, carbon emissions, energy transition

\section{Introduction}

International efforts to lower carbon emissions have largely failed despite the best intent of Kyoto countries. ${ }^{1}$ While Kyoto itself may have lowered emissions from what they would have been otherwise, world emissions continue to rise and the two largest emitters - the United States and China - remain uncommitted to emission reductions. Perhaps more worrying than the upward march in emissions is that ongoing scientific work is now placing more and more emphasis on the stock of cumulative emissions and less on current emission flows. This trend reflects an increased scientific understanding of the slow decay rates of carbon and the long lags in the warming process created by the storage of heat in the deep oceans. As a result, policy makers and politicians alike have now turned to the use of cumulative emissions as a guide to policy. The National Research Council (the publishing arm of the US National Academy) for example recently developed a series of forecasts for climate change based entirely on cumulative emissions.

This recent NRC (2010) study contains two relevant pieces of information for our purposes here. First, by linking cumulative emissions to temperature changes predicted for 2100, the NRC finds an almost linear relationship between cumulative carbon and eventual warming by 2100 . While different paths to the same cumulative emissions exhibit small differences in temperatures over short time periods, over the span of a century it makes little difference whether emissions are primarily front loaded or back loaded. For economists this change in focus

a Canada Research Chair in International, Energy and Environmental Economics, the Department of Economics, University of Calgary Research Associate, NBER.

1 For example, some of the unpleasant facts regarding Kyoto are that emissions of Annex 1 NonEIT signatory countries are $14.9 \%$ above their Kyoto commitments; Canada, Japan and some EU countries have effectively ignored their Kyoto commitments; while India, China, Brazil and the United States account for over $50 \%$ of current emissions and are not limited by any international agreement. 
towards cumulative emissions has several analytical advantages when evaluating our options. The first is simply that the dynamics of temperature change are greatly simplified since they are now tied directly to cumulative emissions. For a broad range of cumulative emissions, temperature changes are simply linear in total emissions making analytical work simple. The second is that since only cumulative emissions matter, we can specify a simple carbon budget that the world must meet by 2100 to hit any temperature target. A set of these potential budgets is illustrated by the graph shown in Figure 1 below where cumulative emitted carbon (measured in 1000s of gigatons) are related to cumulative temperature impacts. The error bars reflect uncertainties in our understanding of the climate system. As shown in the figure, we have emitted a bit more than 500 gigatons currently, and to remain well within the uncertainty band for a 2 degree Celsius increase by 2100 we have perhaps a carbon budget of 500 more gigatons to "spend" over the next 90 or so years.

Figure 1: Cumulative Emitted Carbon (Measured in 1000s of Gigatons) as Related to Cumulative Temperature Impacts

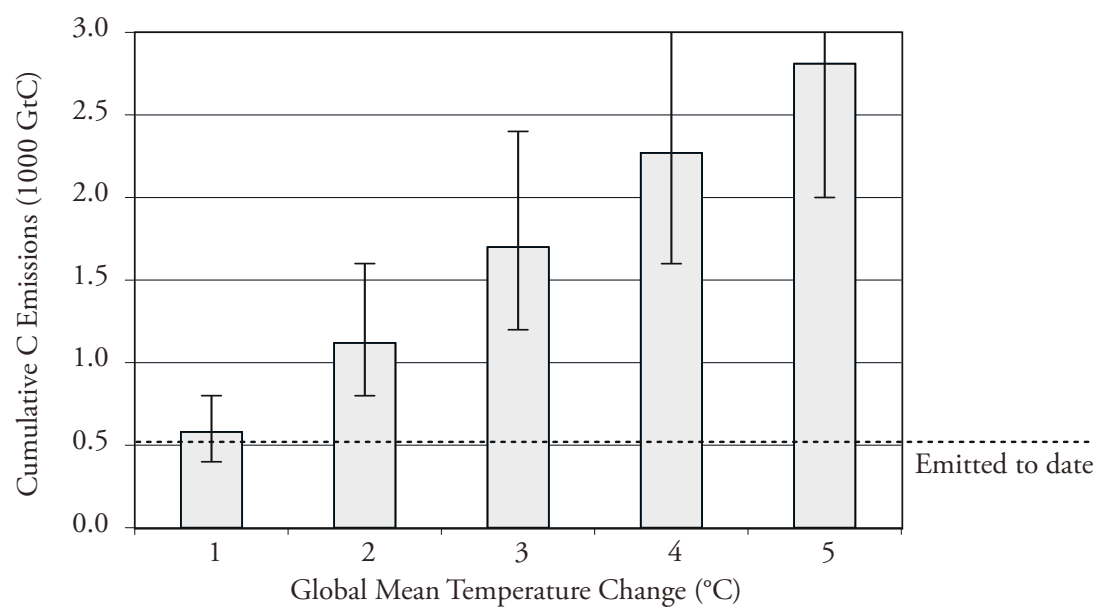

Implicit in the cumulative carbon budget is that the stabilization of any temperature change in 2100 requires the stock of cumulative emissions be held constant thereafter. The implication is fairly shocking: holding the world at any fixed temperature in 2100 will require almost a zero flow of emissions past 2100 . That is, the entire world will need to be carbon neutral by 2100 if temperatures are to stabilize at a warming of $1,1.5,2$, or even 3 degrees Celsius. 


\section{Can Green Energy Save us from Climate Change?}

Answering this question turns out to be far more difficult than it might first appear, since it requires we address four smaller separate questions to generate a complete answer. First, we need to ask what "saving us" from climate change means. Although there are many potential answers, I will assume this implies producing a path for carbon emissions to 2100 that results in a less than 2 degree Celsius (3.6 degree Fahrenheit) increase in temperature. In terms of cumulative emissions, this implies a budget of approximately 500 gigatons carbon in the next 90 years. The 2 degree Celsius target is simple and was adopted by the Cancun Agreement. Second, we need to ask what the world would look like if something radical is not done to hasten the adoption of renewable power worldwide. To answer this question, I need to construct a Business As Usual (BAU) trajectory to develop an expected path for carbon emissions. Third, we need to ask what alternative path with rapid adoption of green power could meet the overall carbon budget. And finally, we need to ask whether the implied shift in the energy mix required to meet the carbon target is in some sense feasible.

\section{Business as Usual}

To construct the BAU path, I calibrate a simple neoclassical growth model that incorporates a role for pollution emissions. Specifically, I use the Green Solow model of BROCK and TAYLOR (2005). The model can be written such that pollution emissions and conventional factor inputs (capital, labor) produce output; and, then by assuming one unit of emissions arises from one unit of dirty fossil energy use, the model can be transformed into one where energy and inputs create output. To calibrate the model, I adopt a set of assumptions implicit in ExxonMobil's Outlook for Energy to 2030 (ExxonMobiL, 2010). This is an annual publication from ExxonMobil that contains forecasts for growth in the developed and developing world, for population growth, and for emission trajectories based on an assumed price per ton of carbon of $\$ 30$ ton $/ \mathrm{CO}_{2}$ in 2020 rising to $\$ 60 /$ ton in 2030. While I do not have access to the model(s) ExxonMobil employs to generate its forecast, it is apparent from the forecasts that the model has strong neoclassical properties just like the Green Solow model. In particular, the forecasts exhibit convergence across regions in both GDP growth rates and emissions per capita while long run growth is tied directly to the rate of technological progress. The major assumptions behind the BAU forecast to 2030 are as follows: the world consists of two regions (OECD, and Non-OECD); world population 
grows by 1 billion by 2030 almost all of it occurring outside the OECD; OECD GDP grows at $2 \%$ per year; Non-OECD grows on average $5 \%$ per year; NonOECD emissions exceed OECD emissions by $40 \%$ in 2010; and, the carbon emissions to GDP ratio decreases at 2.5 to $3 \%$ per year.

With these assumptions in place, the simulation shows OECD emissions fall by about $15 \%$ to 2030 since the decarbonization rate exceeds growth in OECD GDP. In the Non-OECD emissions however double by 2030, and world emissions approach 12 gigatons by 2030 which implies an annual growth rate of about $1 \%$ per year. If we were to simply extrapolate these results from 2030 to 2100 , annual emissions would hit 25 gigatons and cumulative emissions would put us in uncharted waters with a prospective temperature rise of 4-5 Celsius. The point is however that since the model is Neoclassical, a simple extrapolation would be a huge mistake since the Non-OECD cannot grow forever at $5 \%$ per annum, and hence over time these countries will become more and more like their OECD counterparts. To see what the world might look like by 2100, in Figure 2 below I present the model's simulation to 2100 assuming population growth slows to $.5 \%$ per year, and in the long run the Non-OECD has the same rate of technological progress as does the OECD (2\%). The results from this exercise are shown in Figure 2.

As shown OECD emissions continue to decline after 2030, while Non-OECD emissions now peak in 2050 and fall thereafter when their economic growth slows and is eventually more than offset by the relatively fast rate of decarbonization assumed. Despite this somewhat rosy picture of Non-OECD emissions, annual global emissions in 2100 are over 10 gigatons carbon and cumulative emissions reach 1450 gigatons carbon. The temperature implication of this cumulative emission total is perhaps a 3 degrees Celsius increase, with error bands running from 1.75 to 4 Celsius. Moreover, entering 2100 with emissions over 10 gigatons means we face an equally difficult problem then as we do now in reducing emissions.

\section{The Counterfactual and Burden of Green Power}

I now construct a possible scenario that meets the carbon budget constraint by rapidly moving to less carbon intensive green energy. It has to meet two goals: First, it cannot have cumulative emissions much higher than 500 gigatons. Second, annual emissions in the last years have to be close to zero. This scenario is shown in Figure 3.

In constructing this scenario I have assumed Green sources of power are $1 / 6$ as carbon intensive as Brown sources per unit energy delivered. Since the 
Figure 2: Annual and Cumulative Carbon Emissions 2010-2100, BAU Trajectory

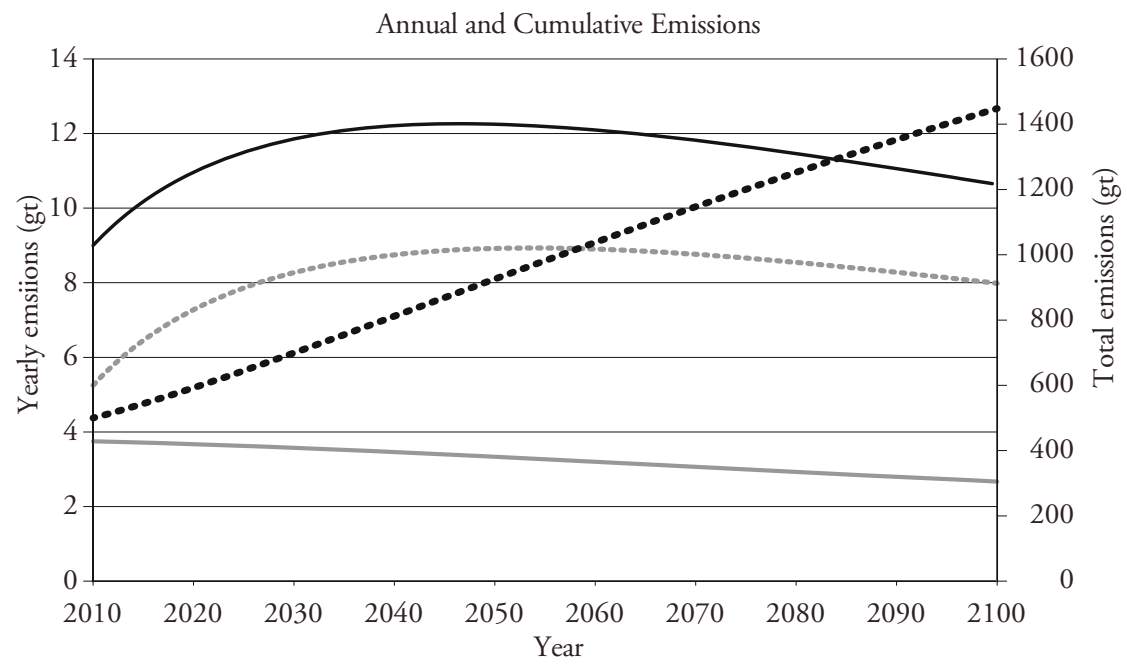

Figure 3: Annual and Cumulative Carbon Emissions 2010-2100, Green Sources of Power Trajectory

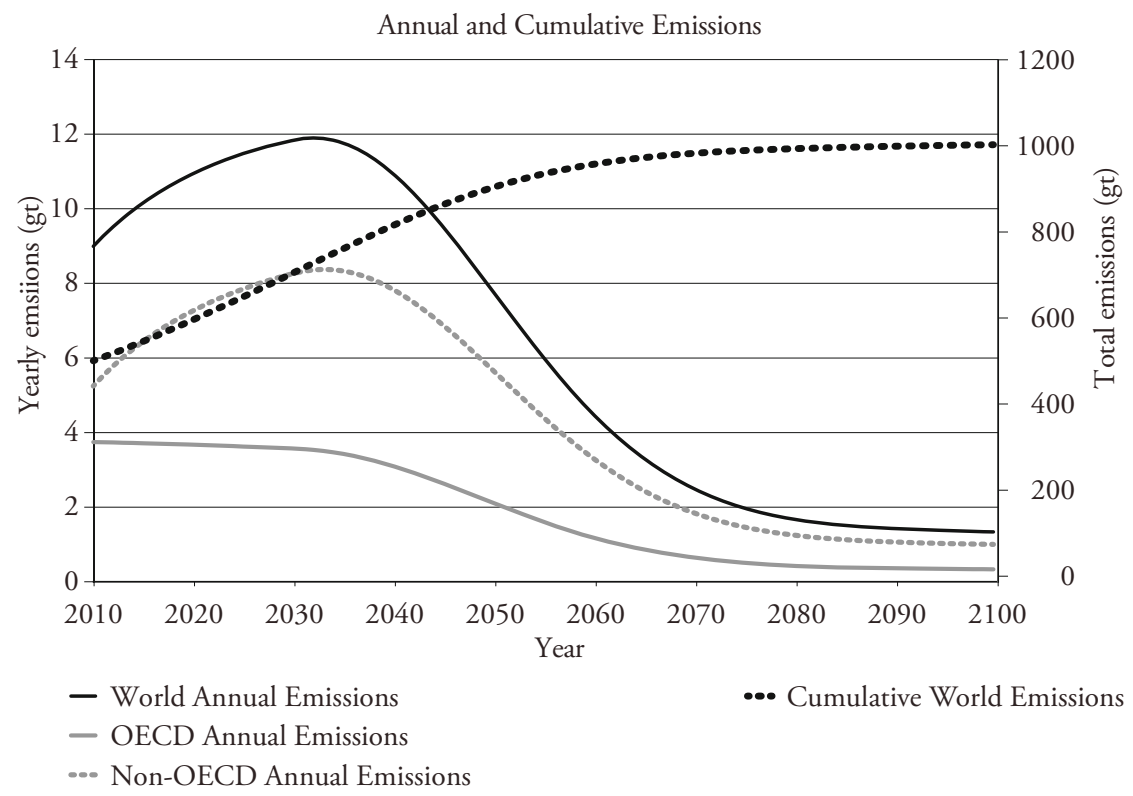

Swiss Journal of Economics and Statistics, 2014, Vol. 150 (1) 
ExxonMobil base case runs to 2030, I only allow Green Power to rise over time starting post 2030, and throughout I assume the rate of economic growth is unaffected by the energy transition. These are clearly heroic assumptions. With this in hand it is now possible to construct a carbon path that meets the 2 degree limit as shown above.

As shown in Figure 3, OECD emissions decline at a faster rate as Green and less carbon heavy power is introduced much more quickly. Similarly, NonOECD emissions peak in 2035, then decline quite rapidly which ensures that cumulative emissions reach approximately 1000 gigatons carbon by 2100 . While annual emissions are not zero in 2100 , they are relatively close to zero giving us some room to reduce emissions further in the coming years. Apart from the usual caveats we would have to such an analysis, the most important consideration should be whether this movement to Green Power is in any sense possible. What it reflects is a huge and very rapid energy transition. For example, if we now compare the business as usual to the Green Power trajectory we can show what it entails for energy supplies. For example, an implication of the trajectory shown above is that Green Power has to deliver the equivalent of 650 quads (quadrillion BTUs) of energy by 2055. This is a large number especially when in 2010 Green Power delivered 65 quads worldwide, and of this biomass provided 47 , hydro 11 , and solar, wind, and other renewables only 7 . Clearly there is a large challenge facing Green Power if it is to be the sole means of meeting our carbon budget by 2100 .

\section{Can it Be Done? What Can History Tell Us?}

Engineering a very rapid energy transition from fossil fuels to Green energy sources is not likely to be easy, although it is difficult to say much more with certainty since there is very little empirical evidence we can bring to bear on this question. What we do know comes from our understanding and documentation of past energy transitions. To this information we can add what we know about the incentives economic agents, both pubic and private, may have to adopt green power rapidly.

There is a large and excellent literature documenting energy transitions, and I cannot begin to even review this material here (see FouQueT, 2010, and SMIL, 2010). Therefore, I will try to stick to facts with little interpretation. The basic facts regarding energy transitions are as follows: 1) There were only two transitions before: biomass to coal and coal to liquid fossil fuels; 2) past transitions were very slow; 3) the transitions were of relatively small magnitude; 4) energy 
sources don't disappear, instead the shares of energy from each source change; 5) new energy sources lead to new converters and prime movers; and, 6) all previous energy transitions have been to higher density sources, that provided new benefits.

For example, using US data we find that in 1885 , coal surpassed wood as the dominant fuel source, but total energy usage was only 6 quads. In 1945, coal was surpassed by petroleum and natural gas as the dominant fuel source with total usage now equal to perhaps 30 quads. In 2010, total US consumption was now approximately 92 quads. Unfortunately, the counterfactual shown in Figure 3 indicates the scale of the needed change to Green Power is on the order of six times the entire US energy consumption since it represents an energy supply of approximately 650 quads in 2055.

Next consider the timing involved again using US figures and dates. From coal's first introduction in 1850 to its complete dominance of energy supply by 1920 , coal took 70 years. Similarly, from the first U.S. oil well in 1880 until their point of maximum dominance in 1970, liquid and gaseous fossil fuels took 90 years. Unfortunately, the counterfactual constructed in Figure 3 indicates the speed of the change to Green Power requires Green Power must move from a small share today to almost complete dominance in 50 years time.

Next consider incentives. Coal's first use was heat; coal was cheaper than wood and only after a period of time did it overtake wood in heating. But the demand for coal brought us a power source - the steam engine. It gave us a power source not tied to rivers, wind or animate power. Later still mobile applications arrived powering trains, ships, and even cars. Finally, the energy density of coal facilitated its use in transportation. Similarly, petroleum was first a lowly lubricant, until the internal combustion engine was invented in the 1880s. Eventually this innovation and the even higher energy density of liquid fossil fuels brought us further mobility and the development of diesel, gasoline, and jet engines. Unfortunately, Green Power does not provide any new benefits in terms of energy density for transport applications. Bio-fuels are less dense energy sources than liquid fossil fuels. Solar, wind, and tidal sources of electricity produce just that - electricity - and provide no new products that may well spur the introduction of new innovations or accelerate adoption. With only a relatively few exceptions worldwide, direct government subsidies or regulations are required for green power to be commercially viable.

The real benefit to green power is not that it offers us advantages in mobility, density, or application that fossil fuels do not have; its advantage is that it is far cleaner in terms of carbon. While this is certainly a huge benefit, this benefit is a public and not a private one; moreover, the good in question - the climate - is 
a global public good. And therein lies the rub: the massive introduction of Green Power will require active government involvement, and will not be the cheapest energy solution absent a worldwide price on carbon. Therefore, the incentives needed for the introduction of Green Power will only be in place if we have an international climate change treaty limiting emissions. In this sense, Green Power cannot save us from the climate change brought about by our failure to sign and enforce a real global agreement; in fact, the massive introduction of Green Power will need such an agreement.

\section{Conclusion}

Unless our current scientific understanding of climate change is radically in error the world's ongoing love affair with carbon based energy sources will imply large temperature changes in the next 100 years. By constructing a business as usual trajectory for the world economy, I showed that while the convergence in growth rates across regions helps, as does ongoing decarbonization of GDP, the business as usual trajectory implies a much warmer world in 2100. I then asked whether a movement to power sources with lower carbon contents - so called Green Power - could save us from breaching the carbon budget associated with a 2 degree Celsius warming by 2100 . Unfortunately, unless the world economy grows much slower, converges faster, and has a smaller population, the challenge for Green Power is daunting. The needed scale, speed and direction of change in energy sources would be unprecedented in human history. Green Power cannot save us from climate change.

\section{References}

British Petroleum (2011), BP Statistical Review of World Energy, London: British Petroleum.

Brock, W., and M.S. TAylor (2010), "The Green Solow Model”, Journal of Economic Growth, 15(2), pp. 127-153.

National Research Council (2010), Climate Stabilization Targets: Emissions, Concentrations, and Impacts over Decades to Millennia, National Academies Press.

Exxon Mobil (2010), The Outlook for Energy: A View to 2030. 
Fouquet, Roger (2010), “The Slow Search for Solutions: Lessons from Historical Energy Transitions by Sector and Service", Energy Policy, 38(11), pp. 6586-6596.

Smil, Vaclav (2010), Energy Transitions: History, Requirements, Prospects, Santa Barbara (CA): Praeger.

\section{SUMMARY}

International efforts to lower emissions have largely failed, and many now believe we will fail to limit warming to less than 2 degrees Celsius by 2100. In this extended abstract, I discuss whether a wholesale movement to renewable energy or Green Power could limit carbon emissions to meet a 2 degree Celsius target while simultaneously meeting the world's growing demands for energy. Using a very simple growth model I calculate the burden Green Power must carry in order to keep emissions within the 2 degree target, and then discuss the speed, scope, and size of the energy transition this would imply. An energy transition of sufficient speed and magnitude to meet these targets is unlikely, leading me to believe that Green Power cannot save us from climate change. 